\title{
Un siglo después de la 'gripe española': contribución de la Gran Guerra y conocimiento del genoma como herramienta para el control de la influenza
}

\author{
Laura Gómez¹, Luis Alberto Gómez² \\ ${ }^{1}$ Escuela Colombiana de Medicina, Facultad de Medicina, Universidad El Bosque, \\ Bogotá, D.C., Colombia \\ ${ }^{2}$ Grupo de Fisiología Molecular, Instituto Nacional de Salud, Bogotá, D.C., Colombia; \\ Departamento de Ciencias Fisiológicas, Facultad de Medicina, Universidad Nacional de \\ Colombia, Bogotá, D.C., Colombia
}

En el 2018 se cumplieron cien años de la pandemia de influenza de 1918. Ya es una costumbre referirse a esta pandemia como la 'gripe española', lo cual es impreciso, ya que en realidad se generó en los Estados Unidos de América, aunque causó millones de muertes en todo el mundo. Un siglo después de su aparición, y 10 años después de haberse superado la emergencia por la influenza $\mathrm{H}_{1} \mathrm{~N}_{1}$ del 2009 iniciada en México, vale la pena que la comunidad científica, en especial la comunidad dedicada a la salud pública en el mundo, discuta sobre los factores determinantes de la aparición de una pandemia por influenza y sobre algunas herramientas indispensables para prepararse ante una emergencia de tal magnitud.

Aunque son muchos los factores sociales, económicos, demográficos, políticos, culturales, genéticos e inmunológicos que pueden determinar el surgimiento de una pandemia, y diversas las herramientas con las que contamos actualmente para enfrentar este tipo de emergencias, cuya revisión completa escapa al propósito de este manuscrito, nuestro objetivo es, en primer lugar, señalar que la pandemia de 1918 surgió como resultado de las condiciones sociopolíticas, económicas, de hacinamiento y de miseria propiciadas por la Primera Guerra Mundial y, en segundo lugar, señalar cómo el conocimiento de la biología molecular sobre los virus de influenza circulantes, que hoy se detectan y caracterizan mediante reacciones de amplificación, como la reacción en cadena de la polimerasa (PCR), y de secuenciación del genoma, contribuye de manera esencial al diagnóstico y a la vigilancia oportuna de la enfermedad que causan, así como a una mayor comprensión de la evolución molecular del virus de la gripe y el diseño de vacunas y modalidades terapéuticas, lo que, sin duda, ayudará a enfrentar de manera más eficaz una potencial epidemia de gripe mortal.

En 1917, los Estados Unidos de América entraron a participar en la

Recibido: 20/08/18

Aceptado: $31 / 01 / 19$

Publicado: $12 / 02 / 19$

Citación:

Gómez L, Gómez LA. Un siglo después de la 'gripe española': contribución de la Gran Guerra y conocimiento del genoma como herramienta para el control de la influenza. Biomédica. 2019;39:17-21

https://doi.org/10.7705/biomedica.v39i1.4884

\section{Correspondencia:}

Luis Alberto Gómez, Grupo de Fisiología Molecular, Instituto Nacional de Salud, Avenida Calle 26 No 5120, Bogotá, D.C., Colombia

Teléfono: (571) 2207700 , extensión 1483 Igomez@ins.gov.co
Primera Guerra Mundial como aliados de Francia, unión que se fortaleció con el reclutamiento y la participación de tropas españolas y de otras partes del mundo $(1,2)$. Con base en algunas fuentes primarias y secundarias de información y en la investigación realizada por la socióloga Beatriz Echeverri Dávila, es posible afirmar que la llamada 'gripe española' tuvo su verdadero origen en el campamento Funston en Kansas (3). Allí se concentraron cerca de 2.200 voluntarios españoles que lucharon en la Legión Extranjera francesa, de los cuales 954 eran jóvenes originarios de Cataluña (2).

Asimismo, trabajadores portugueses y españoles se desplazaron a los países vecinos para abastecer temporalmente la demanda de los trabajadores nativos que habían ido a combate (3). Estos hechos históricos son parte de la información que permite entender algunas de las causas del carácter 
expansivo de la influenza en aquella época. Con la participación de las tropas de Estados Unidos en la guerra, la 'gripe española' llegó a los centros de intercambio de información del ejército en el norte de Francia en 1917 (4) para, de allí, pasar a España, donde hubo cerca de ocho millones de enfermos en Madrid (5) a solo dos meses de haberse presentado en Estados Unidos y un mes después de afectar a Francia (3).

Fue tal el avance de la gripe que, aproximadamente, 18.900 soldados alemanes se infectaron (3), y pronto se extendió a China y Japón (5), como queda evidenciado en un informe firmado por el médico militar Cachie el 13 de mayo de 1918, en el cual señaló el inicio de la pandemia el 30 de abril entre los soldados indochinos (6), en tanto que, ya en abril de 1918, había llegado a México (Soto RA. Temporal and spatial distribution of the 1918 Spanish influenza in México. En: Academy C. (Ed.). Historical influenza pandemics: Lessons learned. Meeting and workshop abstracts. Copenhagen, Denmark; 2010. p. 24.).

En este contexto, la expansión de la gripe española en las distintas regiones y ciudades podría explicarse no solo a partir de la interacción y participación de los distintos cuerpos militares en la guerra, sino también por su ubicación geográfica (5), lo cual constituye un elemento clave de las estrategias de combate, refugio y cuidado de los soldados. En uno de los artículos de El Heraldo de Madrid, titulado "La enfermedad de Madrid", se hizo alusión a la importancia que adquirió la aglomeración y el hacinamiento de las personas para la rápida diseminación y el elevado nivel de contagio que adquirió la influenza, haciendo especial referencia a los soldados heridos que permanecían por largos periodos en condiciones precarias en los centros médicos de atención (2). En el artículo se sugería, además, que en Francia se localizaba un posible foco de infección e, incluso, el lugar de inicio de la pandemia, específicamente en la base del ejército en Étaples (campo de tránsito principal), pues allí se daban las condiciones ideales para la incubación del virus de la influenza debido a la reunión y acúmulo de personas, y a su convivencia con aves de granja o migratorias y con cerdos $(4,5)$.

Otro aspecto estrechamente relacionado con el carácter pandémico que adquirió la influenza hace cien años, fue el aumento exponencial de la pobreza conforme progresaba la guerra, lo que afectó no solo a los militares sino también a la población civil, circunstancia que desencadenó problemas sanitarios por la falta de higiene de las personas. En esa época las medidas de prevención se enfocaron en la limpieza oral, nasal y de las manos; sin embargo, estas eran muy difíciles de llevar a cabo para quienes se encontraban en batalla o carecían de los recursos básicos. Todos estos factores socioeconómicos contribuyeron a la pandemia. Debido a la guerra, durante la primavera no hubo evidencia oficial de la presencia de la influenza en la mayoría de las naciones en combate, por lo que España, afectada por el contagio masivo de la gripe, fue uno de los primeros países que notificó la enfermedad, razón por la cual se adoptó el nombre de 'gripe española' (3).

No solo las condiciones de miseria, hacinamiento, desnutrición y viviendas inadecuadas contribuyeron y dieron pábulo a la enfermedad y a los focos de propagación, sino que también las características infecciosas y virulentas del virus de la influenza $\mathrm{H}_{1} \mathrm{~N}_{1}$ circulante favorecieron su diseminación. Las pandemias de influenza son causadas por la introducción de virus que, generalmente, son subtipos nuevos para la población humana, que causan enfermedad y contra los cuales no se tiene inmunidad, o muy poca, y que se transmiten eficientemente de persona a persona y de un país a otro (7). 
Estos nuevos virus surgen por dos mecanismos que no son mutuamente excluyentes: el reordenamiento de los segmentos genéticos y la transmisión entre especies. Los genomas de los virus de la influenza son cambiantes debido a su alta tasa de mutación y capacidad de reordenarse $(2,8)$.

Los virus de la influenza pertenecen a la familia Ortomixoviridae. Contienen un genoma compuesto de ocho segmentos de ARN de cadena sencilla de sentido negativo y cada segmento codifica una o dos proteínas. Según la capacidad antigénica de sus moléculas de hemaglutinina $(\mathrm{HA})$ y neuraminidasa (NA), estos virus se clasifican en 16 subtipos $\mathrm{HA}\left(\mathrm{H}_{1}-\mathrm{H}_{16}\right)$ y nueve subtipos $\mathrm{NA}\left(\mathrm{N}_{1}-\mathrm{N}_{9}\right)$. La proteína HA es crítica para la unión del virus a los receptores celulares y para su fusión con las membranas del endosoma. La proteína NA es importante para la liberación del virus de las células infectadas, que luego pasa a infectar otras $(8,9)$ y es, además, el blanco de acción de algunos medicamentos antivirales, como el oseltamivir y el sanamivir, entre otros.

Generalmente, las cepas de los virus pandémicos se originan de la asociación de genes de los virus de la influenza de las aves, de los cerdos y de los humanos, es decir, se trata de virus completamente nuevos que no han sido detectados anteriormente en la especie humana y se caracterizan por su gran capacidad para transmitirse entre personas, por lo cual se diseminan globalmente a la mayoría de los países e infectan a un considerable número de personas, especialmente a niños, adultos jóvenes y adultos mayores. La tasa de mortalidad por estos virus es variable $(8,9)$. Debido a estas características, es necesario emplear pruebas moleculares sensibles y específicas para el diagnóstico y la confirmación del tipo de virus causante, las cuales constituyen herramientas poderosas y precisas para enfrentar este tipo de pandemias.

La reacción en cadena de la polimerasa en tiempo real (RT-PCR) se considera la prueba de referencia para la detección molecular de virus de la influenza, debido a que es muy sensible y específica y, conjuntamente con la secuenciación (contenido y orden de nucleótidos) del genoma del virus, son herramientas moleculares esenciales para detectar e identificar los virus nuevos en las vías respiratorias de pacientes con el cuadro clínico y el nexo epidemiológico propios de la infección. Por lo general, se amplifican fragmentos específicos de los genes que codifican para la HA y la NA del virus de la influenza $A$ en muestras de hisopado faríngeo y de tejido pulmonar, mediante RT-PCR convencional. La especificidad de los productos amplificados se confirma mediante análisis de secuencia $(10,11)$.

Tanto las epidemias como las pandemias tienen impactos económicos sustanciales debido a los altos costos de la prevención, el diagnóstico y el tratamiento, así como a los originados por el ausentismo laboral, la atención médica y las hospitalizaciones. Por lo tanto, un diagnóstico rápido y un detallado conocimiento de los mecanismos que determinan la patogenia y la transmisión entre las especies y dentro de ellas, combinados con medidas preventivas y terapéuticas, son elementos críticos para el control de las infecciones por el virus de la influenza (10).

Una potencial limitación de los métodos basados en la PCR es que pueden arrojar falsos negativos debido a eventuales cambios en la secuencia del genoma viral, lo que es particularmente relevante para la detección de virus nuevos. Por lo tanto, el uso de diferentes metodologías, como la construcción de bibliotecas y la secuenciación parcial o total del genoma del virus, permite confirmar los casos sospechosos, así como tipificar las muestras de virus de la influenza de tipo A que no sean detectables con los estuches diagnósticos comerciales basados en la PCR (11). 
El análisis de las secuencias del genoma viral es importante por varias razones. Desde la perspectiva de la prevención y el control de la influenza, se requiere de una cuidadosa vigilancia de la circulación del virus, así como de eventuales cambios a formas más o menos virulentas. Desde una perspectiva científica, la oportunidad de observar la evolución viral en tiempo real, lo cual es posible con la secuenciación, puede proporcionar información oportuna para detectar los factores que determinan su patogenia y transmisibilidad.

Asimismo, esta información es importante para deducir y vigilar si hay cambios en la secuencia que aporten información para entender las adaptaciones virales en los humanos, así como para el desarrollo y mejoramiento de los medicamentos antivirales, el estudio de la potencial resistencia a los medicamentos y el desarrollo de vacunas para el control de este tipo de pandemias.

Por lo tanto, deben vigilarse los cambios en la secuencia que puedan estar asociados con una mayor patogenia y capacidad infecciosa, y con la constitución de segmentos del genoma de diferentes linajes (porcino, aviario y estacional, entre otros) (9); esto podría usarse cuando hay coinfección y un posible reordenamiento de dos tipos de virus para subtipificar las cepas individuales y los potenciales reordenamientos de los diversos serotipos resultantes de otros más complejos (9). Ello plantea la necesidad de continuar desarrollando herramientas moleculares que faciliten la detección de este tipo de cambios, como los microarreglos, la PCR múltiple, la secuenciación de nueva generación y los ensayos de proteómica, entre otros (Gómez LA. Genoma humano y salud pública. En: Malagón-Londoño G, Moncayo-Medina A, editores. Salud pública. Perspectivas. Tercera edición. Bogotá: Editorial Médica Panamericana; 2019. En prensa).

Entre las lecciones aprendidas de este tipo de pandemias está el conocimiento de algunos factores que contribuyen a la diseminación del virus de la influenza, así como la utilidad de la biología molecular para detectar y caracterizar de manera oportuna y rápida los virus circulantes. El análisis de los factores determinantes mencionados y el uso de las herramientas moleculares disponibles son acciones esenciales porque generan la información necesaria que, al ser compartida nacional e internacionalmente, contribuye a estar mejor preparados para la atención y el control oportunos de tales pandemias.

\section{Referencias}

1. Ferro M. La Gran Guerra 1914-1918. Madrid: Alianza Editorial; 2014. p. 9.

2. Gallo MI. La prensa madrileña de información general ante la epidemia de gripe de 1918-19. Medicina \& Historia: Revista de Estudios Históricos de las Ciencias Médicas. 1995, número 57 , p. 1-16.

3. Dávila BE. La gripe española. La pandemia de 1918-1919. Madrid, España: Centro de Investigaciones Sociológicas; 1993. Número 132, p. 102

4. Milne I. Professor John Oxford on the 1918-1919 influenza pandemic (May 17, 2010). Fecha de consulta: 10 de diciembre de 2018. Disponible en: https://puesoccurrences.wordpress. com/2010/05/17/professor-john-oxford-on-the-1918-1919-influenza-pandemic/

5. Ansart S, Pelat C, Boelle PY, Carrat F, Flahault A, Valleron AJ. Mortality burden of the 1918-1919 influenza pandemic in Europe. Influenza Other Respir Viruses. 2009;3:99-106. https://doi.org/10.1111/j.1750-2659.2009.00080.x

6. Erkoreka A. Origins of the Spanish influenza pandemic (1918-1920) and its relation to the First World War. J Mol Genet Med. 2009:3:190-4.

7. Ayora-Talavera G. Influenza: historia de una enfermedad. Revista Biomédica. 1999;10:57-61. 
8. Webster RG, Bean WJ, Gorman OT, Chambers TM, Kawaoka Y. Evolution and ecology of influenza A viruses. Microbiol Rev. 1992;56:152-79.

9. Jang J, Bae SE. Comparative co-evolution analysis between the HA and NA genes of influenza A virus. Virology (Auckl). 2018;9:1178122X18788328. https://doi. org/10.1177/1178122X18788328

10. Ghedin E, Sengamalay NA, Shumway M, Zaborsky J, Feldblyum T, Subbu V, et al. Large-scale sequencing of human influenza reveals the dynamic nature of viral genome evolution. Nature. 2005;437:1162-6.

11. Richt JA, Lager KM, Clouser DF, Spackman E, Suárez DL,Yoon KJ. Real-time reverse transcription-polymerase chain reaction assays for the detection and differentiation of North American swine influenza viruses. J Vet Diagn Invest. 2004;6:367-73. https://doi. org/10.1177/104063870401600501 